\title{
Metáforas e significados do câncer de mama na perspectiva de cinco famílias afetadas
}

\author{
Breast cancer metaphors and meanings \\ from the perspective of five families
}

\author{
1 Instituto de Saúde Coletiva, \\ Universidade Federal da \\ Bahia, Salvador, Brasil. \\ Correspondência \\ J. S. C. Tavares \\ Instituto de Saúde Coletiva, \\ Universidade Federal da \\ Bahia. Rua Padre Feijó 29 \\ 4 o andar, Salvador, $B A$ \\ 40110-170, Brasil. \\ jeanetavares@hotmail.com
}

\begin{abstract}
This article analyzes metaphors and meanings related to breast cancer among families affected by the disease. The first section briefly contextualizes the social construction of meanings related to cancer in the 20th century, with the Brazilian context as the main reference. The next section discusses meanings ascribed to breast cancer in five families that included women who had received a diagnosis of breast cancer and who were (or had been) under in-hospital treatment. The families were part of a qualitative study on patients in a specialized cancer hospital in the State of Bahia. The data analysis showed differences among the concepts associated with cancer and breast cancer, inter-generational sharing of ontological interpretations, reinterpretation of medical discourse based on psychosomatic factors, and notion of cure associated with clinical discharge.
\end{abstract}

Breast Cancer; Disease; Family
Jeane Saskya C. Tavares 1

Leny A. Bomfim Trad 1

\section{Introdução}

A partir da década de 60 do século XX, emergem, com força na problemática social da enfermidade, questões relativas ao modo como diferentes grupos sociais assumem o papel de enfermos ou à percepção que os indivíduos têm dos sintomas da doença 1 . Ambas as questões remetem aos significados atribuídos à saúde e à doença em uma dada sociedade, incluindo aqui o entendimento sobre a causalidade, sintomatologia, estratégia de enfrentamento, dentre outros.

É possível distinguir dois grupos de explicações no que se refere à compreensão acerca da experiência da enfermidade 1 : uma perspectiva (a) individualista, que reduz o comportamento humano diante da enfermidade a questões psicológicas ou (b) uma perspectiva coletivista, para a qual o fator cultural é o núcleo central da análise e enfatiza, portanto, as diferenças de valores e atitudes frente às doenças, traduzidas em diferenças de grupos e de classes sociais, faixas etárias ou etnias.

Uma e outra perspectiva coincidem, entretanto, na compreensão de que a enfermidade consiste em uma experiência e, assim sendo, é resultado de uma interpretação 1 . A enfermidade adquire, portanto, um sentido particular à medida que é interpretada. Assim, a análise dos sentidos particulares deve considerar a construção histórico-social do câncer na configura- 
ção destes significados e interpretações individuais compartilhados nos diferentes grupos sociais. No caso específico do câncer, Gimenes 2 destaca que significados e interpretações acerca do câncer e das situações que lhe estão associadas interferem no processo de enfrentamento e na adaptação às diferentes fases do desenvolvimento e tratamento da doença.

O presente artigo analisa metáforas e significados construídos em torno do câncer em uma dupla perspectiva. Em um primeiro momento, realiza uma breve incursão histórica pelo século XX, detendo-se, sobretudo, no contexto brasileiro, apontando as imagens e significados vinculados ao câncer no decorrer do século. Em seguida, são analisados os significados do câncer de mama para cinco famílias que tinham entre seus membros mulheres que haviam recebido diagnóstico de câncer de mama e que estavam em diferentes estágios da doença e do tratamento num hospital especializado em oncologia da cidade de Salvador, Bahia, Brasil.

A produção dos significados no âmbito das famílias é analisada aqui a partir da perspectiva fenomenológica, centrada na experiência prática no mundo cotidiano. Essa concepção, cuja origem remonta a Husserl 3 , mas que se atualiza em Shultz \& Merleau Ponti 4, valoriza a produção intersubjetiva de sentidos que se dá através dos processos interativos e reconhece o corpo como fundamento indiscutível da inserção do ser no mundo.

Para focalizar a experiência da doença, mais precisamente do câncer de mama, desde a ótica da fenomenologia, foram especialmente úteis as contribuições de Alves 1 e Rabelo et al. 5 . Dois pressupostos, apresentados por esses autores, constituem um referencial teórico de base na condução da nossa problemática. $\mathrm{O}$ primeiro diz respeito à necessidade de compreensão da experiência subjetiva da enfermidade, tendo em vista o seu enraizamento com o contexto cultural. Devendo-se, portanto, considerar os processos sociais pelos quais os indivíduos definem e legitimam tal experiência, assim como, comunicam e negociam os significados relativos a ela para os demais 5 .

O segundo pressuposto justifica a ênfase em torno dos processos interativos em estudos que focalizam a experiência de doença e cura em contextos médicos plurais, uma vez que, nesses casos, os indivíduos percorrem diferentes instituições terapêuticas e se utilizam, via de regra, de abordagens, por vezes contraditó- rias, para diagnosticar e tratar a doença. Revela-se, assim, o caráter fluido e mutável das definições referentes à doença e aflições dela advindas, que se inscreve em uma complexa dinâmica relacional, na qual ganha destaque o papel das redes sociais no processo de orientação e sustentação dos significados e comportamentos frente à doença 5 .

\section{Câncer: construção histórico-social dos significados}

No século XIX e início do século XX, o câncer, além de considerado contagioso, era associado à falta de limpeza, à sujeira física e moral. Considerava-se que, principalmente no caso das mulheres, o adoecimento era resultado de "pecados e vícios”, em especial nas práticas sexuais 6 . Como aponta Bertolli Filho 7, entre práticas sexuais consideradas "monstruosas", o coito bucal era identificado como causa principal das neoplasias nas mulheres homossexuais ou bissexuais, formando-se nódulos cancerosos inicialmente na cavidade bucal e trato digestivo, seguindo-se a disseminação por todo o organismo. Entretanto, alguns estudos realizados no século XIX indicavam a associação entre o câncer e pessoas submetidas ao excesso de esforço e atividades, assim como pessoas sobrecarregadas de emoções que deveriam ser refreadas 8 .

As orientações sanitárias quanto à etiologia e às possibilidades de cura do câncer disseminadas pelos órgãos de saúde eram confusas e divergentes entre si 7 . A medicina educadora dessa época listava diversos elementos próprios da vida civilizada na era industrial como possíveis causas do câncer, destacando-se o alcatrão emanado das vias asfaltadas, a poeira das ruas, os gazes liberados pelos motores em funcionamento ou chaminés industriais, a proximidade constante de geladeiras elétricas e uso de sapatos apertados ou de saltos altos. A atitude moralizadora e higienista, encontrada no Brasil nas primeiras décadas do século XX, norteava as ações dos órgãos de saúde pública, que, como estratégia de intervenção sanitária para o câncer, a tuberculose e a sífilis, aconselhavam o isolamento e desinfecção minuciosa das residências em caso de morte dos doentes.

Associando-se o câncer à pobreza e à sujeira física e moral, os enfermos dessa terrível moléstia eram duplos inimigos da sociedade, pois não contribuíam para a produção de riqueza coletiva e oneravam os cofres públicos do Esta- 
do e os privados da filantropia 7. O paciente de câncer, além de moralmente deturpado, era considerado um cidadão que não assumia sua parcela de responsabilidade social, pois deixava propositadamente de seguir as regras de higiene.

Entretanto, numa interpretação benéfica do adoecimento, esse era um castigo através do qual o moribundo poderia alcançar a redenção, caso houvesse resignação diante da dor e do sofrimento. Conforme discute Sant'Anna 6, seguindo essa concepção, para o doente, era indicado o estoicismo, a temperança diante das aflições da vida, conforme o ideal de equilíbrio e refreamento preconizados na época. Padecer de câncer era sofrer um castigo "redentor", que resultava em libertação, elevação espiritual para o doente e sacralização do seu corpo.

Em relação à atitude dos médicos, durante a primeira metade do século passado, considerava-se um ato de crueldade informar ao paciente o diagnóstico ou os efeitos dos medicamentos utilizados e apenas à família eram dadas essas informações. Dessa forma, mulheres com câncer de mama tinham acesso a pouca ou nenhuma informação especializada sobre seu estado de saúde, viam-se diante de uma conspiração silenciosa entre sua família e a equipe médica, contando com pouco suporte social além do oferecido pelos familiares 9 . Além da desinformação e passividade, eram freqüentes as complicações pós-cirúrgicas como linfedema do braço afetado, depressão, ansiedade, diminuição da auto-estima e das funções física e sexual das pacientes mastectomizadas 10 .

Fazem parte, portanto, da história do enfrentamento do câncer até os anos 40 do século XX o pudor, a vergonha, o isolamento e o silêncio, que afetavam particularmente as mulheres com câncer de mama, ameaçadas pela mutilação de um dos principais símbolos de sua feminilidade. No entanto, a partir dos anos 50 , ocorreram mudanças consideráveis nos significados e formas de enfrentamento do câncer socialmente recomendados.

Essas mudanças foram incentivadas pelos movimentos sociais em defesa dos direitos das mulheres, mas deveram-se, em grande parte, aos avanços nos métodos de diagnóstico e tratamento (associação entre quimioterapia e radioterapia), que possibilitaram o aumento do número de sobreviventes e do tempo de sobrevida dos pacientes. O acompanhamento prolongado desses pacientes indicou a necessidade de lhes proporcionar boa qualidade de vida e a importância do estudo das repercussões e adaptação psicossociais dos pacientes, de suas famílias e dos profissionais de saúde em onco- logia. A medicina oficial começou a admitir a possibilidade de participação de fatores internos (psicológicos) para o desenvolvimento do câncer.

Como analisa Sontag 8, a noção moralizadora do câncer como castigo que se ajusta ao pecador, tão comum no século XIX e nas três primeiras décadas do século XX, foi sendo gradativamente substituída pela noção de que a doença ajusta-se e exprime o caráter do paciente. Se, no primeiro caso, a doença era vista como uma resposta a uma conduta desregrada de indivíduos, cujos comportamentos e emoções eram desmedidos, na segunda, a causa estaria relacionada justamente com a contenção do desejo ou não-expressividade das emoções.

Nessa concepção, o candidato ideal ao câncer tem a personalidade marcada pela passividade, pouca emotividade, regularidade dos hábitos, baixa agressividade ou negação da hostilidade, depressão e dificuldade na formação de vínculos afetivos. Nesse momento, já não se considera mais o pecado ou a elevada carga de atribuições responsável pelo desenvolvimento da doença, mas sim um tipo de personalidade específica do próprio homem - o chamado "Tipo C” 11. Uma personalidade mal-adaptada, oposta ao consumismo e produtividade exigidos pela sociedade neoliberal do fim do milênio.

Argumentos a favor dos aspectos psíquicos na etiologia do câncer já existiam desde a medicina galênica, no entanto, é na segunda metade do século XX que a interpretação psicossomática da doença ganha notoriedade, e novas formas de interpretação sobre etiologia e de enfrentamento do câncer são indicadas. São clássicos os métodos de tratamento e estudos que associam o câncer às características de personalidade e indicam tratamentos baseados na espontaneidade e liberação de sentimentos "negativos" acumulados, estímulo a vencer o câncer através de uma atitude mental positiva, alteração da autopercepção e manutenção de níveis altos de qualidade de vida.

É esperado e estimulado o papel ativo do doente, que de vítima passou a ser agente de sua cura. Enfrentar o câncer nesse momento histórico, particularmente para os homens, implicava em lutar brava e diariamente, em conhecer seu próprio corpo, sua subjetividade e, principalmente, falar, expor sua doença e história de vida. No caso específico do câncer de mama, apenas a partir da década de 70, seguindo um movimento internacional, as experiências das mulheres mastectomizadas passaram a receber atenção especial pela mídia 6 .

Essa mudança nos significados e formas de enfrentamento do câncer contribuiu para o de- 
senvolvimento de novas teorias e tratamentos mais eficientes, aumento da capacidade de gerenciamento do estado de saúde e elevação da qualidade de vida do doente. Porém, a concepção de que o caráter do doente é responsável pelo desenvolvimento do câncer pode mostrarse tão ou mais punitiva que a noção da doença como castigo. De certa forma, os argumentos morais e sexuais são mantidos e atualizados na incapacidade dos doentes em aceitar e exprimir seus próprios desejos 8 .

No século XXI, apesar de todo o avanço alcançado nas pesquisas dos fatores genéticos, em seu diagnóstico e tratamento, o câncer permanece como uma doença de causa obscura e cujo tratamento ainda não é totalmente eficaz. A literatura médica e as campanhas governamentais realizadas neste novo milênio destacam o papel da determinação genética e as repercussões da "vida moderna" associando-os aos fatores de risco para o desenvolvimento dos tumores da mama 12 .

Nos meios de comunicação e propagandas governamentais, a organização e hábitos da vida urbana são novamente responsabilizados por expor os indivíduos aos fatores ambientais que atacam o organismo do homem moderno: a ingestão de anticoncepcionais e gravidez tardia, fumo, emissão de raios, dietas alimentares, produtos industrializados, poluição, alimentos alterados geneticamente, numa extensa lista de possíveis agentes carcinogênicos. A desordem genética que gera o câncer está associada à modernidade, numa atualização das considerações sobre a "vida civilizada" do início do século XX.

Nessa breve exposição histórica, percebese que o câncer tem sido associado à dor, à morte, à culpa, ao medo e, sobretudo, à estigmatização social. A alta incidência, as repercussões psicossociais e as incertezas quanto à etiologia e ao tratamento revestem o câncer de valor simbólico especial, situando-o, no Ocidente, como um dos mais "perigosos e enigmáticos" males, uma doença metáfora 8 .

Os objetos de medo mais profundos são identificados com o câncer, que passa a adjetivar, tornando-se ele mesmo uma metáfora: os sentimentos relacionados com o mal são projetados no câncer, e esse - enriquecido de significados - é projetado no mundo ${ }^{8}$. É, portanto, uma doença sobrecarregada de significados, que tentam dar sentido e, por fim, controlar, ainda que ilusoriamente, a doença, a vida e a morte.

Concordando com Laplantine 13, mesmo considerando a variabilidade individual e social, existem permanências da experiência mór- bida e da esperança de cura perfeitamente identificáveis. Nesse sentido, a despeito dos avanços tecnológicos, observa-se a coexistência e atualização das diferentes noções e significados históricos apresentados, que são particularmente construídos, legitimados e compartilhados no âmbito familiar acerca do câncer e sua cura. Os dados extraídos do estudo empírico, que apresentaremos mais adiante, reforçam essa hipótese de atualização desses significados e um certo grau de hibridização. Ou seja, aos velhos significados somam-se outros, construídos intersubjetivamente a partir da experiência da doença.

\section{Metodologia}

Tal como pontua Minayo 14, as categorias saúde ou doença trazem uma carga histórica, cultural, política e ideológica que não pode ser contida apenas numa fórmula numérica ou num dado estatístico. Nesse sentido, ao buscar conhecer os significados associados ao câncer de mama compartilhados nos grupos familiares de mulheres com essa doença, privilegiamos uma abordagem metodológica de cunho etnográfico.

Foram adotados os seguintes procedimentos de coleta de dados:

(a) Ficha de consulta aos prontuários médicos - para coleta sistemática das informações relevantes sobre diagnóstico e estadiamento do câncer de mama, histórico e quadro clínico no início da pesquisa, tipo de tratamento proposto/realizado, doenças prévias, observações da equipe de saúde sobre a evolução da paciente. (b) Roteiro de entrevista semi-estruturada enfocando os dados de identificação dos entrevistados, histórico de experiências anteriores da família com outras doenças e com o câncer, modelos explicativos desenvolvidos pela família sobre o câncer, seu tratamento e enfrentamento, alterações da rotina familiar e emoções experimentadas após o diagnóstico de câncer, estratégias adotadas para lidar com o diagnóstico/tratamento do câncer, expectativas quanto ao tratamento, planos e avaliação do grupo sobre seu futuro.

(c) Genograma - em um plano mais geral visou traçar a genealogia familiar, permitindo, no seu desenvolvimento e análise, tal como sugere McDaniel et al. 15, a identificação de eventos disruptivos associados com adoecimento na família, assim como, a apreensão de mitos e padrões familiares relativos ao processo saúdedoença. Simultaneamente, elaboravam-se "linhas de tempo" nas quais eram dispostos cro- 
nologicamente os principais fatos relacionados à saúde na história de cada família.

É importante salientar que, durante as entrevistas, houve o cuidado de utilizar inicialmente o termo "problema de saúde" em vez de câncer de mama, sendo que o mesmo era substituído pelos termos utilizados pelo paciente ou familiares para designar o câncer.

Os participantes deste estudo foram selecionados entre famílias de pacientes atendidos no Hospital Aristides Maltez (HAM), uma instituição filantrópica especializada em oncologia, centro de referência em assistência médica, pesquisa e ensino, localizada na cidade de Salvador. A identificação de possíveis participantes se deu através de consultas em prontuários, aos profissionais do serviço de psicologia da instituição, apresentação da pesquisa nos grupos de atendimento às famílias de pacientes terminais e de mulheres mastectomizadas, além de indicações das próprias pacientes.

Procurou-se incluir pacientes com diferentes perfis de evolução, tempo de doença, estrutura familiar e funcionamento social. Por isso, foram utilizados como critérios de inclusão das pacientes: idade entre 18 e 65 anos, recebimento do diagnóstico há menos de 10 anos e residência na cidade de Salvador. Não foram incluídos pacientes ou familiares que apresentassem distúrbios orgânicos cerebrais, estados psicóticos secundários ao abuso de drogas (incluindo álcool) ou deficiência mental já diagnosticada.

Foram considerados "familiares" aqueles referidos pela paciente como tal, indicando vínculo biológico, afetivo ou de conjugalidade com a mesma, independente de existir vínculo jurídico. A família é, dessa forma, considerada um grupo social, cujos membros mantêm um sistema de relações significativas entre si 16 , do qual a paciente com câncer de mama é um dos membros.

As cinco famílias selecionadas para o estudo tinham, entre seus membros, uma mulher que havia recebido diagnóstico de câncer de mama e que esteve ou estava em tratamento no hospital. Ao todo, foram entrevistadas 21 pessoas, sendo 5 pacientes e 16 familiares. A idade das pacientes variou entre 46 e 52 anos, em sua maioria estavam casadas há mais de 20 anos e tinham 2 ou 3 filhos. Exceto no caso da família $\mathrm{A}$, os filhos das pacientes estavam na fase da adolescência ou eram adultos jovens na época do recebimento do diagnóstico de câncer de mama.

As primeiras entrevistas foram realizadas na própria instituição, respeitando as normas e rotinas dos atendimentos médicos e psicológicos oferecidos aos pacientes e familiares. Após o consentimento das pacientes, procedeu-se à observação nos domicílios acompanhada das entrevistas individuais e/ou grupais, de acordo com a disponibilidade das famílias.

O processo de análise de dados baseou-se na abordagem hermenêutica proposta por Minayo 14 , que enfatiza a necessidade de ultrapassar-se a incerteza em relação à leitura e percepção do pesquisador sobre o conteúdo coletado. Dessa forma, após audição e leitura exaustiva das entrevistas, buscou-se compreender significações, conteúdos e estruturas latentes relacionados com três categorias principais de análise: concepções sobre a enfermidade, a etiologia e a cura do câncer; levando em consideração o contexto sócio-cultural no qual esses elementos estavam inseridos.

No processo de sistematização e análise dos dados, utilizou-se como ferramenta complementar o programa QSR-NUDIST - Vivo (Qualitative Solutions \& Research - Nonnumerical, Unstructured Data) que permite a sistematização e o gerenciamento de dados etnográficos digitalizados, substituindo os sistemas de classificação por meio de fichas, sendo de responsabilidade do(s) pesquisador(es) a criação e interpretação das categorias analíticas.

Tendo em vista o recorte deste artigo, que adota como unidade de observação e análise a família, as narrativas selecionadas não buscam enfatizar a percepção de nenhum dos seus membros de forma particular; pretende, antes, apreender como o problema é percebido e definido nas famílias.

Por fim, ressalta-se que foram cumpridas todas as determinações da Resolução 196/96 (Conselho Nacional de Saúde - CNS) sobre pesquisa com seres humanos e que a coleta de dados iniciou-se após aprovação do protocolo e projeto, elaborados de acordo com as diretrizes do CNS, pelo Comitê de Ética em Pesquisa (CEP) da instituição em que o estudo foi realizado. Nesse sentido, os nomes utilizados para identificação dos informantes são fictícios.

\section{Resultados e discussão}

\section{Concepções sobre a enfermidade: o câncer versus o câncer de mama}

Um primeiro aspecto a destacar com relação às concepções sobre o câncer nas famílias estudadas, extraído a partir da análise dos genogramas, refere-se ao compartilhamento intergeracional dos significados no interior das famílias. Observou-se uma convergência de percepções entre os membros das famílias das diferentes 
faixas etárias sobre a letalidade do câncer e o sofrimento provocado pelo tratamento.

Nos depoimentos dos participantes, percebeu-se a diferenciação entre o que entendem por câncer, a doença maligna, e o câncer de mama, uma manifestação branda da doença. Nas caracterizações sobre o câncer, houve o predomínio do que Laplantine 13 denomina de modelo ontológico de interpretação da doença, ou seja, o câncer é identificado como um "ser”, o "flagelo", a "coisa" que invade, degenera o corpo e transforma o paciente num não-ser. Vale notar que as definições mais radicais e enfáticas sobre o câncer como doença fatal e associada a sofrimento insuportável foram encontradas nas famílias nas quais havia casos de morte por câncer ou de pacientes com metástase e na fase terminal da doença.

Os relatos das famílias coincidem, como aponta Sant'Anna 6, com a imagem do câncer encontrada em grande parte dos depoimentos e na literatura sobre o tema: bicho que devora o corpo do paciente. Os participantes referem-se a uma sentença de morte, uma doença mortal e de rápida evolução, uma doença traiçoeira, uma espécie de inimigo latente que se desenvolve com extrema rapidez após ser descoberto. De modo geral, são usados adjetivos radicais, associados ao terror e recobertos por mistério.

“Ai! Câncer é uma praga, é uma.... é uma miséria viu? (...) é horrível a metástase come o corpo (...) eu acho que é pior do que a AIDS, porque a AIDS por mais que... por ser um vírus que não tenha cura, mas prolonga a vida muito ... não tem uma rapidez como o câncer, o câncer de uma hora pra outra a metástase já tá comendo seu... seu... seu estômago, já tá pro fígado come (...) então corrói tudo de uma hora pra outra" (Carla, filha de paciente, 22 anos).

Esses resultados concordam com as pesquisas nacionais e internacionais realizadas sobre o tema, nas quais o câncer é representado como algo negativo, invasivo, traumático, limitante, que remete ao medo e à dor tanto para os pacientes quanto para os familiares. Esses significados podem ser uma das causas da constante utilização de figuras de linguagem para referir-se ao câncer, dos pactos de silêncio desenvolvidos intra e extra grupo familiar, da evitação de comportamentos preventivos e para a tendência a postergar a busca pelo diagnóstico.

Contrariamente ao termo câncer, o câncer de mama foi identificado como uma forma de câncer de menor periculosidade, um mal menor quando comparado à manifestação em outros órgãos. Dessa forma, embora haja ênfase do câncer como doença fatal e com aspectos sobrenaturais, o perigo da doença é relativizado pelos participantes conforme o tipo de câncer em questão:

“(...) se não cuidar mata. Morre como qualquer outra doença, tem doenças piores. (...) se ele não for agressivo demais você convive com ele muitos anos. Eu, um dia, fui a uma reunião lá (no hospital) tinha uma senhora com vinte anos de mastectomizada... a não ser que ele seja agressivo demais, você viu Mário Covas com toda força, e muita, foi embora, né?" (Ivan, marido de paciente, 52 anos).

Essa percepção é associada, nos depoimentos, à possibilidade de esconder os efeitos da doença e da mastectomia. A "invisibilidade" dos resultados da cirurgia e a sobrevivência das pacientes são considerados fatores que minimizam a gravidade desse tipo de câncer, pois não expõe a paciente à vergonha e ao preconceito. Por não ser um órgão de importância vital, a crença de que a retirada da mama promove a resolução imediata da doença também contribui para a percepção de menor gravidade desse tipo de câncer.

No entanto, o sofrimento causado pelas repercussões da quimioterapia e da mastectomia para auto-imagem da mulher e na sexualidade do casal é reconhecido pela maioria dos participantes. As marcas deixadas no corpo pela mastectomia impressionam, e tanto pacientes quanto familiares evitam visualizá-las:

“(...) eu tava olhando o processo feio que é o processo cicatricial então isso mexe comigo entendeu? ... aquele medo assim da... da do seu corpo daquela mudança que é uma retirada é um processo de extração de uma parte de seu corpo que você gosta, que você não quer que tire e que se você mesmo reconstituindo não vai ficar a mesma coisa, não vai ficar perfeito como era entendeu? (...) porque você fica usando uma prótese de silicone, eu acho que até na, na sua vida se você tem um parceiro... deixa a mulher inibida aquela coisa da queda da auto-estima" (Ingrid, filha de paciente, 20 anos).

Devido à dor e ao sofrimento gerados, a quimioterapia parece receber o status de doença. Isso porque, na maioria dos casos, foi esse tratamento a principal fonte de sofrimento devido à despersonalização e estigmatização para pacientes e familiares:

"O que eu sabia que eu tava com câncer era exatamente as quimioterapias que eu tomava, porque eu me olhava no espelho e via uma criatura totalmente sem um fio de cabelo, sem sobrancelha, sem cílio, quer dizer... você não se sente nem mulher, sabe? (...) Quando você olha pro teu corpo que você não vê um pêlo no teu braço, um pêlo em canto nenhum do teu corpo, aí você olha pro espelho ai você não vê sobran- 
celha, você não vê cílio, quer dizer... poxa você tá.... diante de um mostro, é esquisito, é feio. (...) Era outra pessoa que estava ali, não era Alana, não era Alana-alegria, não era Alana-mãe, não era Alana que gostava de brincar tá entendendo? Era uma coisa que estava ali fingindo que era Alana (...)" (Alana, paciente, 49 anos).

\section{Etiologia do câncer}

Nas explicações dos participantes acerca da etiologia do câncer de mama, pode-se observar a combinação entre o desequilíbrio interno (psíquico), social (particularmente na relação com familiares), espiritual e biológico. Mescladas aos argumentos biomédicos, foram identificadas noções do câncer como castigo pelo pecado, como fruto da sobrecarga de emoções e trabalho e expressão do caráter da paciente, de modo geral, em desequilíbrio com a sociedade em que vive.

Ao se referirem aos aspectos biológicos do câncer, os participantes apropriam-se do discurso médico com o qual tiveram contato não só durante o tratamento das pacientes, como também através da literatura especializada e propagandas veiculadas pelos meios de comunicação. Foram citados elementos como traumas físicos (queda/ pontapé, relatados pelos participantes com baixa escolaridade), a idade das pacientes (acima de 35 anos), a hereditariedade, sendo essa relacionada tanto à consangüinidade como à ocorrência de outros casos de câncer na família:

“Não, nem me passou pela cabeça [prevenção do câncer de mama], e principalmente de mama porque muita gente diz que... é hereditário né? E quando... é difícil ter uma pessoa ter câncer de mama se não tiver alguém na família e até agora na família não... não tem ninguém, eu sou a primeira. Eaté que o de bexiga, como é hereditário, eu podia... eu ficava assim 'meu Deus eu tenho que me cuidar'. Eu faço preventivo todo ano, eu tenho que me cuidar porque possa a ser que venha acontecer, agora de mama não, de mama eu não esperei que viesse acontecer" (Sônia, paciente, 45 anos).

Nas explicações espirituais, há ênfase na predestinação, na vontade de Deus e no pecado como aspectos decisivos no adoecimento. Para os participantes, a surpresa e a dificuldade de aceitar o adoecimento são geradas pelo fato de a paciente ser considerada uma "boa pessoa”. Na maioria dos casos, considerou-se que a paciente não deveria ter adoecido, uma vez que não havia cometido um "erro" tão grave que provocasse o câncer, e, portanto, gerasse culpa e sofrimento merecidos.
Entre as famílias estudadas, as explicações psicossomáticas foram as que receberam maior ênfase. No surgimento do câncer, destacam-se como deflagradores da doença o "sofrimento retido", o "guardar rancor", a "amargura":

"Porque eu, eu tenho pra mim que o câncer da minha mãe foi um problema psicológico (...) ela carregou muito assim a responsabilidade de dentro de casa, porque meu pai ficou desempregado durante quase dez anos (...) Isso tudo foi mexendo e segundo os estudiosos tudo o que a mulher absorve, a mama que pega isso né? Que é a parte mais sensível da mulher (...) O psicológico dela, ela, ela absorveu muito essas coisas" (Elisa, filha de paciente, 25 anos).

“(...) Tudo que eu sofria ficava calada e não contava a minha família entendeu? Guardava, um dia explode né? Como se diz mesmo? Você guarda, guarda, guarda um dia aparece né isso? (...) minha doença foi toda isso viu? O desgosto da minha vida mesmo guardando, guardando, guardando acaba nisso. A doença tava retida, acho que tudo isso desgosto de família mesmo entendeu?" (Célia, paciente, 54 anos).

Embora seja comum a descrição do "Tipo C” de personalidade, nas explicações que consideram aspectos psicossomáticos, o câncer é associado aos sentimentos considerados "negativos” pelos entrevistados. Parece que qualquer comportamento ou traço de personalidade avaliados como prejudiciais para os participantes são associados à gênese do câncer. Dessa forma, são apontados não só traços depressivos e melancólicos da personalidade de quem adoece como também traços de ansiedade e agressividade como possíveis causas do adoecimento.

\section{A cura do câncer}

Prevalece nas famílias estudadas a noção do câncer como doença incurável atualmente. No entanto, indicam esperança no desenvolvimento científico e tecnológico que promovam a cura e destacam aspectos que favoreceriam melhores resultados no tratamento e prevenção como a associação entre tratamentos médicos e espirituais, e comportamentos voltados para promoção da saúde.

Os comportamentos que, segundo os participantes, poderiam prevenir o surgimento ou a recidiva do câncer relacionam-se principalmente ao fato de cuidar-se e à manutenção de elevada qualidade de vida. O que significa desenvolver hábitos saudáveis relacionados à alimentação e a atividades físicas semanais, assim como melhoria nas relações sociais.

Corroborando as observações anteriores sobre a diferenciação entre câncer e câncer de 
mama, exceto na família de Alana, a cura do câncer de mama é considerada possível e foi alcançada através do tratamento médico. Esse tipo de câncer não é reconhecido como manifestação de uma doença crônica, prevalecendo, entre os entrevistados, a noção de que a paciente já alcançou a cura, pois não está mais em tratamento hospitalar. Dessa forma, ao minimizar o perigo e a letalidade do câncer de mama, nega-se também a necessidade de alterações comportamentais imediatas nas práticas de cuidados com a saúde.

Entretanto, ainda que as famílias reconheçam e enfatizem a cura nos casos em que houve sucesso no tratamento e evolução positiva no quadro clínico, chama atenção a ansiedade compartilhada por todos os participantes gerada pela ameaça constante de recidiva da doença, ameaça de surgimento e morte entre os membros da família:

“(...) Quem será a próxima vítima? Na árvore genealógica já foi minha avó, minha tia, minha mãe. Será se é minha irmã, se a gente vai ter, quando vai ter, entendeu? Sei lá, fica uma, uma interrogação, uma agonia" (Ingrid, filha de paciente, 20 anos).

Considerando as metáforas utilizadas pelos participantes para o câncer e seu principal método de tratamento, percebe-se que, como apontam Alves \& Rabelo 17, esse é o meio por excelência de fabricação de imagens sugestivas das concepções e valores existentes sobre a experiência da enfermidade. Observa-se que os significados sobre o câncer de mama para as famílias pesquisadas resultam de processos de reinterpretação e filtragem do discurso biomédico, aliado a sentidos presentes no imaginário social sobre a enfermidade, historicamente construídos. Deve-se ressaltar ainda o caráter dinâmico dos significados apreendidos, posto que eles se transformavam ao longo da trajetória da enfermidade.

\section{Considerações finais}

A compreensão da enfermidade pelos atores sociais dá-se numa dupla dimensão temporal: ocorre tanto em decorrência das mudanças da doença no decorrer do tempo, quanto das reinterpretações acerca dessa por parte dos atores envolvidos. Ou seja, a cada fase da doença emergem novos significados relativos a causas ou possibilidades de cura.

São interpretações que ocorrem dentro de um conhecimento construído através de um ciclo de referências que inclui a família, as amizades, a vizinhança e os terapeutas. A doença é, portanto, um conhecimento recorrente e processual, isto é, um conhecimento continuamente reformulado e reestruturado em cada processo interativo específico, resultante da variedade de explicações individuais oferecidas para cada enfermidade.

Através da interpretação da sua experiência, a pessoa adquire um sentido dentro da compreensão humana para sua enfermidade. Cada doença traz um novo sentido à pessoa, a enfermidade significa, conforme relembra Alves 1 (p. 269): “as impressões sensíveis, como uma matéria bruta, só serão organizadas se apreendidas num significado que as torne compreensíveis."

Além disso, ao registrar a tendência entre os familiares a considerar que o câncer de mama se limitou ao período de crise e que as pacientes não eram portadoras de uma doença crônica, os resultados desta investigação indicaram a necessidade de melhor entendimento das noções de ser ou estar doente desenvolvidas por famílias de pacientes. Isso porque, assim como os outros significados, esses podem estar associados ao pouco cuidado de si e das mulheres enfermas.

Vale salientar que, embora seja importante que a população e os profissionais de saúde reconheçam a contribuição dos fatores psicológicos na etiologia e no tratamento do câncer, a interpretação linear e superficial da relação entre personalidade e câncer pode ser altamente prejudicial. Como aponta Sontag 8 , entre as possíveis conseqüências danosas desse tipo de interpretação está o enfraquecimento da capacidade de compreensão do alcance do cuidado médico, que dificulta a adesão do paciente ao tratamento, pois o ônus da doença lhe é atribuído.

Aliado a isso, a "responsabilidade" do paciente pelo adoecimento implícita nessa concepção pode gerar culpa e condená-lo a ser também o responsável por sua cura, entendida como resultado da sua capacidade de ter amorpróprio. A mesma autora destaca que a principal vantagem em centralizar o processo de adoecimento no caráter do doente seria garantir algum controle, uma forma de triunfar, ainda que momentaneamente sobre a própria morte, que, em última instância, passa a ser também um fenômeno psicológico.

Por outro lado, como adverte Kleinman 18, situar a origem do problema de saúde no indivíduo apresenta algumas limitações importantes. Sob essa ótica, a responsabilidade da doença (illness) recai principalmente (embora não totalmente) sobre o paciente. Essa crença é comum em especial no mundo Ocidental, esti- 
mulada por programas do governo de educação para a saúde, e os problemas de saúde são atribuídos, cada vez mais, à "negligência" com relação à alimentação, ao vestuário, à higiene, ao estilo de vida, a relacionamentos, exercício físico e aos vícios - fumo e álcool. O problema de saúde passa a ser visto como uma evidência dessa negligência, e a vítima deve sentir-se culpada por tê-lo provocado.

\section{Resumo}

O presente artigo analisa metáforas e significados construídos em torno do câncer de mama por famílias afetadas por essa enfermidade. A primeira parte do artigo apresenta uma breve contextualização da construção social dos significados do câncer no decorrer do século XX, tendo como referência principal o contexto brasileiro. Posteriormente, são analisados os significados atribuídos ao câncer de mama por cinco famílias que tinham, entre seus membros, mulheres que haviam recebido diagnóstico positivo para o câncer de mama e que estiveram ou estavam em tratamento hospitalar. Essas famílias integraram um estudo qualitativo realizado na Bahia, com pacientes de um hospital especializado em câncer. Na análise dos dados, identificaram-se: diferenças entre as concepções associadas ao câncer e ao câncer de mama, compartilhamento intergeracional de interpretações ontológicas, reinterpretação do discurso médico a partir de considerações psicossomáticas, além da noção de cura associada à alta médica.

Câncer de Mama; Doença; Família

\section{Colaboradores}

J. S. C. Tavares conduziu a pesquisa que derivou no artigo, redigiu a maior parte do conteúdo do artigo enviado, participou do processo de revisão do artigo (versões 1, 2 e 3), colaborou na redação da carta de resposta ao editor. L. A. B. Trad orientou o desenvolvimento da pesquisa que derivou no artigo, sugeriu a concepção geral do artigo, redigiu segmentos do artigo, conduziu o processo de revisão do artigo (versões $1,2,3)$, redigiu a carta de resposta ao editor em colaboração com a outra autora. 


\section{Referências}

1. Alves PC. A experiência da doença: considerações teóricas. Cad Saúde Pública 1993; 3:263-71.

2. Gimenes MG. A pesquisa do enfrentamento na prática psico-oncológica. In: Carvalho MMJ, organizador. Psico-oncologia no Brasil: resgatando o viver psico-oncologia. São Paulo: Summus; 1998. p. 232-46.

3. Huserl E. The crisis of European sciences anda transcendental phenomenology. Evanston: Northwestern University Press; 1970.

4. Merleau-Ponty M. Fenomenologia da percepção. São Paulo: Martins Fontes; 1994.

5. Rabelo MCM, Alves PC, Souza IM. Experiência de doença e narrativa. Rio de Janeiro: Editora Fiocruz; 1999.

6. Sant'Anna DB. A mulher e o câncer na história. In: Gimenes MG, organizador. A mulher e o câncer. São Paulo: Editorial Psy; 1997. p. 43-70.

7. Bertolli Filho C. Fontes para o estudo do câncer em São Paulo. In: Temas em Psico-oncologia, III Encontro e I Congresso de Psico-oncologia. São Paulo: Medina; 1996. p. 8-12.

8. Sontag S. La enfermidad y sus metáforas y el sida y sus metáforas. Madrid: Taurus; 1996.

9. Holland JC. Historical overview. In: Holland JC, Rowland JH, editors. Handbook of psychooncology: psychological care of the patient with cancer. New York: Oxford University; 1990. p. 3-12.

10. Rowland JH, Holland JC. Interpersonal resources: social support. In: Holland JC, Rowland JH, editors. Handbook of psychooncology: psychological care of the patient with cancer. New York: Oxford University; 1990. p. 58-71.
11. Carvalho VA. Personalidade e câncer. In: Carvalho MMJ, organizador. Introdução à psico-oncologia. Campinas: Editorial Psy; 1994. p. 65-78.

12. Instituto Nacional do Câncer. A epidemiologia do câncer. http://www.inca.org.br (acessado em 09/ Nov/2003)

13. Laplantine F. A antropologia da doença. São Paulo: Martins Fontes; 1991.

14. Minayo MCS. O desafio do conhecimento: pesquisa qualitativa em saúde. São Paulo: Editora Hucitec; 1992.

15. McDaniel SH, Hepworth J, Doherty WJ. Os desafios da doença crônica. In: McDaniel SH, Hepworth J, Doherty WJ, organizadores. Terapia familiar médica. Porto Alegre: Artes Médicas; 1994. p. 179-204.

16. Cerveny C. A família como modelo: desconstruindo a patologia. São Paulo: Editorial Psy; 1994.

17. Alves PC, Rabelo MC. Significação e metáforas: aspectos situacionais no discurso da enfermidade. In: Pitta AMR, organizador. Saúde e comunicação. São Paulo: Editora Hucitec; 1995. p. 217-35.

18. Kleinman A. Concepts and a model for the comparasion of medical systems as cultural systems. In: Currer C, Stacey M, editor. Concepts of health illness and disease. A comparative perspective. New York: Berg Publishers; 1986. p. 29-47.

Recebido em 24/Set/2003

Versão final reapresentada em 03/Set/2004

Aprovado em 20/Set/2004 